\title{
Effect of solvent polarity on extraction yield and antioxidant properties of phytochemicals from bean (Phaseolus vulgaris) seeds
}

\author{
Haq Nawaz"1, Muhammad Aslam Shad', Najiha Rehman², Hina Andaleeb ${ }^{1}$, Najeeb Ullah ${ }^{\circledR 1}$ \\ ${ }^{1}$ Department of Biochemistry, Bahauddin Zakariya University, Multan, Pakistan, ${ }^{2}$ Institute of Chemical Sciences, Bahauddin \\ Zakariya University, Multan, Pakistan
}

\begin{abstract}
The effect of solvent polarity on extraction yield and antioxidant properties of phytochemical compounds in bean seeds was studied. Seed flour of three varieties of bean was extracted in a series of organic solvents with increasing polarity ( $n$-hexane, petroleum ether, chloroform, ethyl acetate, ethanol, acetone and water). Preliminary screening of phytochemicals showed the presence of tannins, flavonoids, cardiac glycosides, anthocyanins, terpenoids, carotenoids, ascorbic acid and reducing compounds in all extracts. One way analysis of variance (ANOVA) of results showed that extraction yield, phytochemical content and antioxidant properties were significantly influenced $(p<0.05)$ by the polarity of extracting solvents. The regression analysis of data showed polarity-dependent second order polynomial variations in the extraction yield, phytochemical contents, antioxidant activity, reducing properties and free radical scavenging activity of each variety. Extraction in highly polar solvents resulted in high extract yield but low phenolic and flavonoid content as compared to non-polar ones. The polarity-dependent increase in total antioxidant activity and reducing properties indicates the extraction of strong antioxidant compounds in polar solvents. The study suggests the use of a combination of polar and nonpolar solvents to increase the extraction efficiency of phytochemicals with good antioxidant quality from the bean and other legume seeds.
\end{abstract}

Keywords: Beans seeds/antioxidant properties. Phaseolus vulgaris/phytochemical composition. Regression analysis. Solvent polarity.

\section{INTRODUCTION}

Phytochemicals are non-nutrient bioactive compounds found in fruits, vegetables, cereals, legumes and most of the medicinal plants. These compounds possess antioxidant properties and reduce the risk of oxidative damages imposed by free radicals produced during the normal metabolism (Guevara-González, 2006; Brewer, 2011; Coles, 2013). The human body has developed efficient mechanisms in order to neutralize the adverse effects of oxidative damage either by blocking the production of free radicals or by enhancing the production of endogenous antioxidants (Masella et al., 2005). Antioxidant compounds also help to delay and inhibit the lipid oxidation process to minimize the rancidity, retard the formation of toxic products, help to maintain

\footnotetext{
*Correspondence: H. Nawaz. Department of Biochemistry, Bahauddin Zakariya University, Multan-60800, Pakistan. Tel: 092-061-9210391. Email: haqnawaz@bzu.edu.pk
}

the nutritional quality and increase the shelf life of food materials (Brewer, 2011; Coles, 2013).

The extraction and purification of phytochemical and antioxidant substances from the plant material are generally affected by various factors including time, temperature, solvent concentration and solvent polarity. Depending on chemical nature, various phytochemicals are extracted in solvents of different polarity as no single solvent may be reliable to extract all the phytochemical and antioxidant compounds present in the plant material (Lapornik, Prosek, Wondra, 2005; Iloki-Assanga et al., 2015). Serial exhaustive extraction method involves the successive extraction with solvents of increasing polarity from non-polar ( $n$-hexane) to more polar solvent (water) to ensure the extraction of a wide range of compounds with different polarity (Das, Tiwari, Shrivastava, 2010; Bimakr et al., 2011; Abdel-Aal, Haroon, Mofeed, 2015). Studies have reported that solvent polarity significantly affects the extract yield and antioxidant activity of phenolic compounds in plant material (Ghasemzadeh, 
Jaafar, Rahmat, 2011; Ghasemzadeh et al., 2015; Barchan et al., 2014).

Beans botanically known as Phaseolus vulgaris have been used as foodstuff and fodder for cattle throughout the world. It has been reported that commonly used species of the bean are the good source of proteins, carbohydrates, fiber and minerals along with significant amount of phytochemical and antioxidant compounds. Bean seeds are medicinally important due to their antioxidant, anticancer, antimicrobial, antiobesity, cardioprotective, hepatoprotective and antiproliferative activities (GuevaraGonzález, 2006; Zhu, Jiang, Thompson, 2012; GuajardoFlores, Serna-Saldívar, Gutiérrez-Uribe, 2013; Ortega et al., 2013; Zou, Chang, 2014). In continuity of previous findings, we planned to investigate the effect of solvent polarity on extraction efficiency of phytochemical compounds and antioxidant activity of three varieties of bean (white beans, red kidney beans and small common beans) by consecutive extraction in a series of seven solvents with increasing polarity order ( $n$-hexane, petroleum ether, chloroform, ethyl acetate, ethanol, acetone and water). The results may provide significant data on the suitability of solvents for the extraction of phytochemicals and antioxidants from plant materials particularly beans.

\section{MATERIAL AND METHODS}

\section{Sampling}

The dried seeds of three varieties of beans (white beans, red kidney beans and small common beans) were purchased from the local market and transported to the laboratory. The mature and healthy seeds were separated manually, cleaned from dust, ground to a fine powder using pestle and mortar and sieved through an 80 mesh sieve to obtain the sample of fine particle size $(<50 \mu \mathrm{m})$. The flour obtained was dried under shade at $35 \pm 5^{\circ} \mathrm{C}$ to minimize the moisture content $(<2 \%)$, packed in air tight black coated glass jars and stored at sterile laboratory conditions until further analysis.

\section{Preparation of extracts}

The extracts were prepared by consecutive extraction method using a series of organic solvents with increasing polarity order in terms of their dipole moments (hexane: 0.0 , petroleum ether: 0.1 , chloroform: 4.1 , ethyl acetate: 4.4, ethanol: 4.9, acetone: 5.1 and water: 9.2 D). The flow sheet for entire extraction procedure is given in Figure 1. The seed flour $(20 \mathrm{~g})$ was extracted in $n$-hexane $(100 \mathrm{~mL})$ for $24 \mathrm{~h}$ at room temperature $\left(25 \pm 5^{\circ} \mathrm{C}\right)$ using mechanical shaker (KS/HS 501 Digital Orbital And Reciprocal Shaker,
Thomas Scientific Inc. USA). The extract was evaporated to dryness, weighed and the total extractable components (TEC) were calculated using Eq. 1.

$$
\operatorname{TEC}(\%)=\frac{\text { Weight of extract }}{\text { Weight of sample }} \times 100
$$

The residue obtained after extraction in hexane was further extracted consecutively with petroleum ether, chloroform, ethyl acetate, ethanol, acetone and water. The residue obtained in previous extraction step was extracted in next solvent and the extracts obtained in each extraction step were collected, dried and weighed for calculation of TEC as shown in flow sheet. The dried extracts were then dissolved in the respective solvent $(10 \mathrm{mg} / 100 \mathrm{~mL})$ and used for phytochemical and antioxidant analysis.

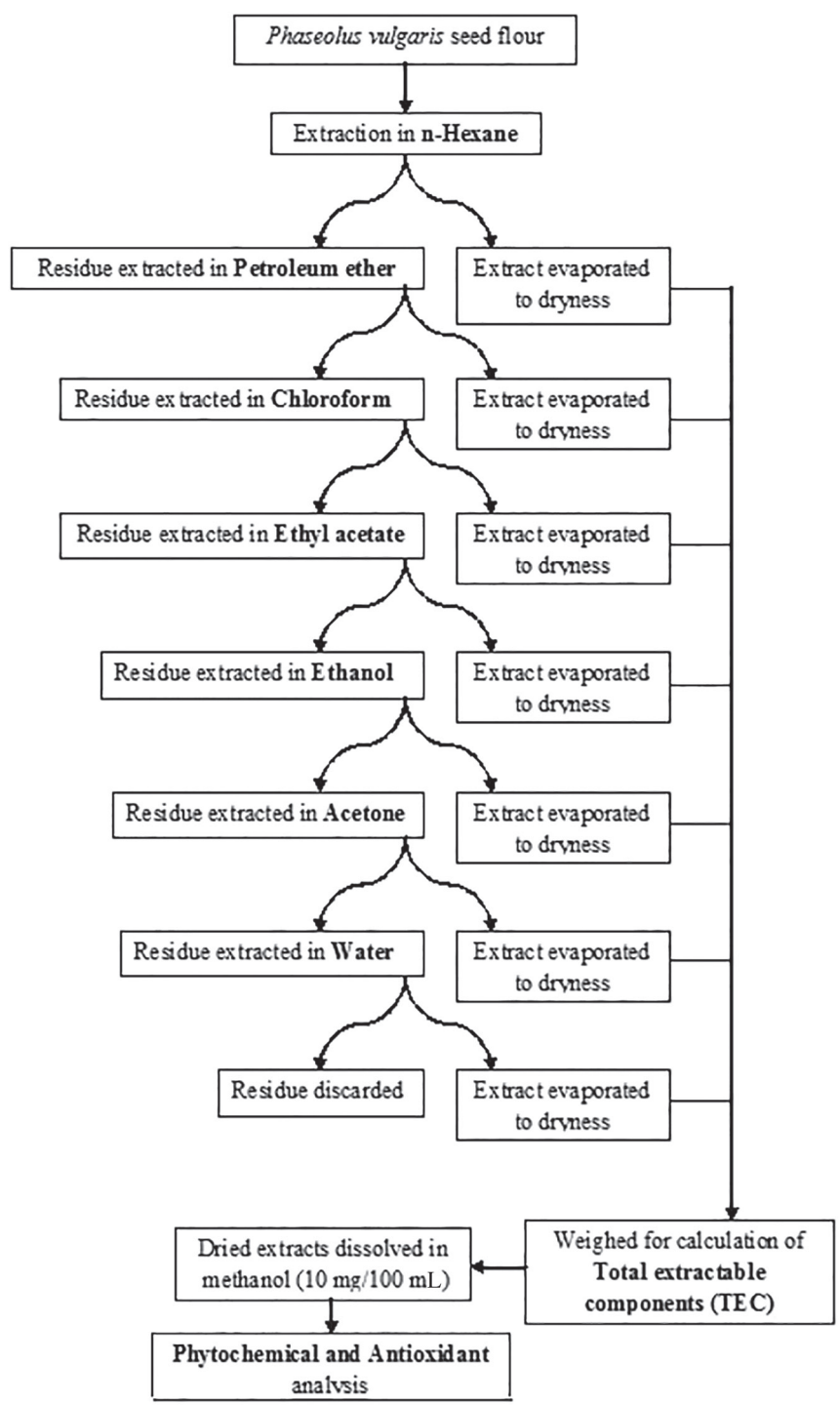

FIGURE 1 - Experimental scheme for extraction of phytochemicals. 


\section{Preliminary screening of phytochemicals}

Preliminary screening of phytochemicals including tannins, saponins, flavonoids, cardiac glycosides, anthocyanins, terpenoids, phlobatannins, free anthraquinones, bound anthraquinones, carotenoids and reducing compounds present in bean seeds was done by methods described earlier (Sofowora, 1982; Trease, Evans, 1989; Harborne, 1998).

\section{Phytochemical and antioxidant analysis}

Total phenolic content (TPC) was determined by previously described Folin-Ciocalteu's method (Shad et al., 2012). TPC were calculated as gallic acid equivalent $\mathrm{g} / 100 \mathrm{~g}$ dry wt. using the regression equation (Eq. 2) obtained from the standard curve of gallic acid $\left(R^{2}=0.987\right)$.

$$
\operatorname{TPC}(g / 100 \mathrm{~g} \text { drywt. })=\text { Abs.at } 720 \mathrm{~nm} / 2.45
$$

Total flavonoid content (TFC) was determined by reported method (Soares et al., 2003) with few modifications. TFC was calculated as catechin equivalent $\mathrm{g} / 100 \mathrm{~g}$ dry wt. using following regression equation (Eq. 3) obtained from the standard curve of catechin anhydrate $\left(R^{2}=0.996\right)$.

$$
\operatorname{TFC}(g / 100 \mathrm{~g} \text { dry wt. })=\text { Abs.at } 500 \mathrm{~nm} / 4.64
$$

Trolox equivalent total antioxidant activity (TAOA) of extracts was determined by previously described phosphomolybdenum assay (Prieto, Pineda, Aguilar, 1999). TAOA was calculated as g/100 g dry wt. using following regression equation (Eq. 4) obtained from the calibration curve of Trolox $\left(R^{2}=0.9772\right)$ :

$$
\text { TETAOA }(\mathrm{g} / 100 \mathrm{~g} \text { drywt. })=\text { Abs.at } 695 \mathrm{~nm} / 1.29
$$

Reducing potential of extracts was determined in terms of iron reducing capacity (IRC) and linoleic acid reducing capacity (LARC) by the methods reported earlier (Osawa, Namiki, 1981; Oyaizu, 1986).

Free radical scavenging capacities of extracts were determined in terms of hydroxyl radical scavenging capacity (HRSC) and DPPH [2,2-diphenyl-1-picryl hydrazyl] radical scavenging capacity (DPPH RSC) by using procedures reported in the literature (Smirnoff, Cumbes, 1989; Sánchez-Moreno, Larrauri, Saura-Calixto, 1998).

\section{Statistical analysis}

All the procedures for extraction, phytochemical analysis, and antioxidant studies were repeated in triplicate. The results were expressed as means \pm standard deviation of three parallel replicates. The means were separated by one-way analysis of variance (ANOVA) at confidence level $p \leq 0.05$ by applying Tukey's multiple range tests using statistical software SPSS version 19.0. The data were analyzed by regression model to study the polarity dependent variation in phytochemical composition and antioxidant profile of bean seed extracts.

\section{RESULTS AND DISCUSSION}

Phytochemical screening of bean seeds extracts in various solvents confirmed the presence of tannins, flavonoids, cardiac glycosides, anthocyanins, terpenoids, carotenoids, reducing compounds and ascorbic acid in each extract of each variety (Table I). However, the presence of saponins, phlobatanins and anthraquinones were not confirmed in any of the extracts. The results were in partial agreement with those reported earlier in bean seeds (Atchibri et al., 2014; Pradeepkumar et al., 2015).

The effect of solvent polarity on extraction efficiency of phytochemical and antioxidant compounds of three varieties of bean was studied by consecutive extraction in a series of solvents with increasing polarity (n-hexane, petroleum ether, chloroform, ethyl acetate, ethyl acetate, ethanol, acetone and water). The extract yield was calculated as total extractable components (TEC) which ranged from $0.24 \pm 0.11-7.23 \pm 0.47 \mathrm{~g} / 100 \mathrm{~g}$ dry wt. (Figure 2A). Total phenolic content (TPC) and total flavonoids content (TFC) of the extracts ranged from $10 \pm 4-101 \pm 10$ and $8 \pm 2.4-70 \pm 9.05 \mathrm{mg} / 100 \mathrm{~g}$ dry wt. respectively while Trolox equivalent total antioxidant activity (TAOA) ranged from $0.15 \pm 0.05-2.53 \pm 0.23 \mathrm{~g} / 100$ g dry wt. (Figure 2B-D). Reducing potential of extracts was estimated in terms of iron reducing capacity (IRC) and linoleic acid reduction capacity (LARC) which ranged from $0.18 \pm 0.08-0.75 \pm 0.65$ (Abs. at $\lambda=700 \mathrm{~nm}$ ) and $18.50 \pm 2.61-47 \pm 3.31 \%$ respectively (Figure $3 \mathrm{~A}, \mathrm{~B}$ ). Free radical scavenging capacities of extracts were determined as hydroxyl radical scavenging capacity (HRSC) and DPPH radical scavenging capacity (DPPH RSC) which were found to be in the range of $32 \pm 2.92-93 \pm 4.40$ and $18 \pm 2.10-43 \pm 3.12 \%$ respectively (Figure $3 \mathrm{C}, \mathrm{D}$ ).

One way analysis of variance (ANOVA) of the results showed that extraction yield, phytochemical content and antioxidant properties of bean seeds were found to be significantly influenced $(p<0.05)$ by increasing 
the polarity of extracting solvents except for TFC and IRC of white beans. The regression analysis of data showed a polarity dependent polynomial variation in all of the studied parameters of each bean variety. The generalized polynomial regression equations obtained by suggested model, regression coefficients and significance values for studied parameters are given in Table II.

A significant positive polynomial response of TEC

TABLE I - Phytochemical screening of bean seeds extracts in various solvents

\begin{tabular}{|c|c|c|c|c|c|c|c|c|c|c|c|c|c|c|c|c|c|c|c|c|c|}
\hline \multirow{2}{*}{ Screening tests } & \multicolumn{7}{|c|}{ White beans } & \multicolumn{7}{|c|}{ Red kidney beans } & \multicolumn{7}{|c|}{ Small common beans } \\
\hline & $\mathbf{H E}^{*}$ & PeE & ChE & $\mathbf{E a E}$ & $\mathbf{E E}$ & $\mathbf{A E}$ & WE & HE & PeE & ChE & EaE & $\mathbf{E E}$ & $\mathbf{A E}$ & WE & HE & PeE & ChE & $\mathbf{E a E}$ & EE & $\mathbf{A E}$ & WE \\
\hline Saponins & - & - & - & - & - & - & - & - & - & - & - & - & - & - & - & - & - & - & - & - & - \\
\hline Cardiac glycosides & + & + & + & + & + & + & + & + & + & + & + & + & + & + & + & + & + & + & + & + & + \\
\hline Anthocyanins & + & + & + & + & + & + & + & + & + & + & + & + & + & + & + & + & + & + & + & + & + \\
\hline Terpenoids & + & + & + & + & + & + & + & + & + & + & + & + & + & + & + & + & + & + & + & + & + \\
\hline Anthraquinones & - & - & - & - & - & - & - & - & - & - & - & - & - & - & - & - & - & - & - & - & - \\
\hline Carotenoids & + & + & + & + & + & + & + & + & + & + & + & + & + & + & + & + & + & + & + & + & + \\
\hline Reducing Compounds & + & + & + & + & + & + & + & + & + & + & + & + & + & + & + & + & + & + & + & + & + \\
\hline Ascorbic acid & + & + & + & + & + & + & + & + & + & + & + & + & + & + & + & + & + & + & + & + & + \\
\hline
\end{tabular}

TABLE II - Regression analysis and one way analysis of variance (ANOVA) of phytochemical composition and antioxidant properties of bean seed

\begin{tabular}{|c|c|c|c|c|c|}
\hline Property & Variety & Regression equation & ${ }^{\prime \prime} \mathbf{R}^{2}$ & Pred. $\mathbf{R}^{2}$ & ${ }^{* * *} \mathbf{P}$-value \\
\hline \multirow{3}{*}{$\begin{array}{l}\text { TEC } \\
\text { (g/100g dry wt.) }\end{array}$} & WB & $\mathrm{TEC}=0.0792 X^{2}-0.3221 X+0.636$ & 0.9725 & 0.9725 & 0.00 \\
\hline & RKB & $\mathrm{TEC}=0.1367 X^{2}-0.5489 X+0691$ & 0.9921 & 0.9254 & 0.00 \\
\hline & $\mathrm{SCB}$ & $\mathrm{TEC}=0.0753 X^{2}-0.2746 X+0.612$ & 0.9225 & 0.9906 & 0.00 \\
\hline \multirow{3}{*}{$\begin{array}{l}\text { TPA } \\
\text { (g/100g dry wt.) }\end{array}$} & WB & $\mathrm{TPA}=0.0007 X^{2}-0.012 X+0.0614$ & 0.8411 & 0.8356 & 0.00 \\
\hline & RKB & $\mathrm{TPA}=0.011 X^{2}-0.0153 X+0.0612$ & 0.934 & 0.9205 & 0.00 \\
\hline & $\mathrm{SCB}$ & $\mathrm{TPA}=0.0007 X^{2}-0.0139 X+0.0815$ & 0.7118 & 0.7067 & 0.00 \\
\hline \multirow{3}{*}{$\begin{array}{l}\text { TF } \\
\text { (g/100g dry wt.) }\end{array}$} & WB & $\mathrm{TF}=0.0004 X^{2}-0.007 X+0.0347$ & 0.5455 & 0.8655 & 0.62 \\
\hline & RKB & $\mathrm{TF}=0.001 X^{2}-0.0013 X+0.0487$ & 0.5563 & 0.543 & 0.00 \\
\hline & $\mathrm{SCB}$ & $\mathrm{TF}=0.0003 X^{2}-0.0093 X+0.068$ & 0.8672 & 0.546 & 0.00 \\
\hline \multirow{3}{*}{$\begin{array}{l}\text { TETAOA } \\
\text { (g/100g dry wt.) }\end{array}$} & WB & TETAOA $=0.0307 X^{2}-0.1785 X+0.494$ & 0.8889 & 0.8768 & 0.00 \\
\hline & RKB & TETAOA $=0.0573 X^{2}-0.3006 X+0.426$ & 0.9813 & 0.9761 & 0.00 \\
\hline & $\mathrm{SCB}$ & TETAOA $=0.0384 X^{2}-0.2493 X+0.609$ & 0.9333 & 0.924 & 0.00 \\
\hline \multirow{3}{*}{$\begin{array}{l}\text { IRC } \\
\text { (Abs.at } 700 \mathrm{~nm})\end{array}$} & WB & $\mathrm{IRC}=0.0058 X^{2}-0.0053 X+0.3084$ & 0.5965 & 0.5978 & 0.47 \\
\hline & RKB & $\mathrm{IRC}=0.0054 X^{2}-0.0074 X+0.287$ & 0.6494 & 0.7042 & 0.00 \\
\hline & $\mathrm{SCB}$ & $\mathrm{IRC}=0.0069 X^{2}-0.014 X+0.2619$ & 0.7055 & 0.6539 & 0.00 \\
\hline \multirow{3}{*}{ LARC (\%) } & WB & LARC $=0.3391 X^{2}-0.9829 X+20.256$ & 0.8577 & 0.8654 & 0.00 \\
\hline & RKB & $\mathrm{LARC}=0.2622 X^{2}-0.4199 X+22.77$ & 0.827 & 0.8509 & 0.00 \\
\hline & $\mathrm{SCB}$ & LARC $=0.3925 X^{2}-0.951 X+22.927$ & 0.8449 & 0.8318 & 0.00 \\
\hline \multirow{3}{*}{$\operatorname{HRSC}(\%)$} & WB & $\mathrm{HRSC}=0.2181 X^{2}-7.1778 X+74.11$ & 0.7899 & 0.7879 & 0.00 \\
\hline & RKB & $\mathrm{HRSC}=0.5616 X^{2}-0.1202 X+35.485$ & 0.974 & 0.9726 & 0.00 \\
\hline & $\mathrm{SCB}$ & $\mathrm{HRSC}=0.2933 X^{2}-3.1876 X+38.468$ & 0.8362 & 0.7207 & 0.00 \\
\hline \multirow{3}{*}{ DPPH RSC (\%) } & WB & DPPH RSC $=-0.4458 X^{2}+3.808 X+20.571$ & 0.5637 & 0.5669 & 0.00 \\
\hline & RKB & $\mathrm{DPPH} \mathrm{RSC}=-0.6702 X^{2}+5.9405 X+21.505$ & 0.5745 & 0.5806 & 0.00 \\
\hline & $\mathrm{SCB}$ & $\mathrm{DPPH} \mathrm{RSC}=-0.6731 X^{2}+6.4319 X+18.884$ & 0.5219 & 0.5168 & 0.02 \\
\hline
\end{tabular}

$* \mathrm{R}^{2}$ : Regression coefficient. ${ }^{* *} \mathrm{p}$-value show the significant difference between the extracts of a single bean variety in different solvents at the confidence level $p<0.05$ using Tukey's multiple range test. $X$ : Solvent polarity, WB: white beans, RKB, red kidney beans, SCB: small common beans 
towards solvent polarity was observed with a high value of regression coefficient $\left(\mathrm{R}^{2}=0.9225-0.9921\right)$ for each variety (Figure 2A). Extract yield was found to be comparatively high in water, a polar solvent, than that in nonpolar solvents. The high value of TEC in polar solvent indicates the presence of more polar and water soluble components in bean seeds as compared to non polar ones. TPC and TFC were also found to be polynomial functions of solvent polarity with relatively higher values of $\mathrm{R}^{2}$ (TPC: 0.700 -
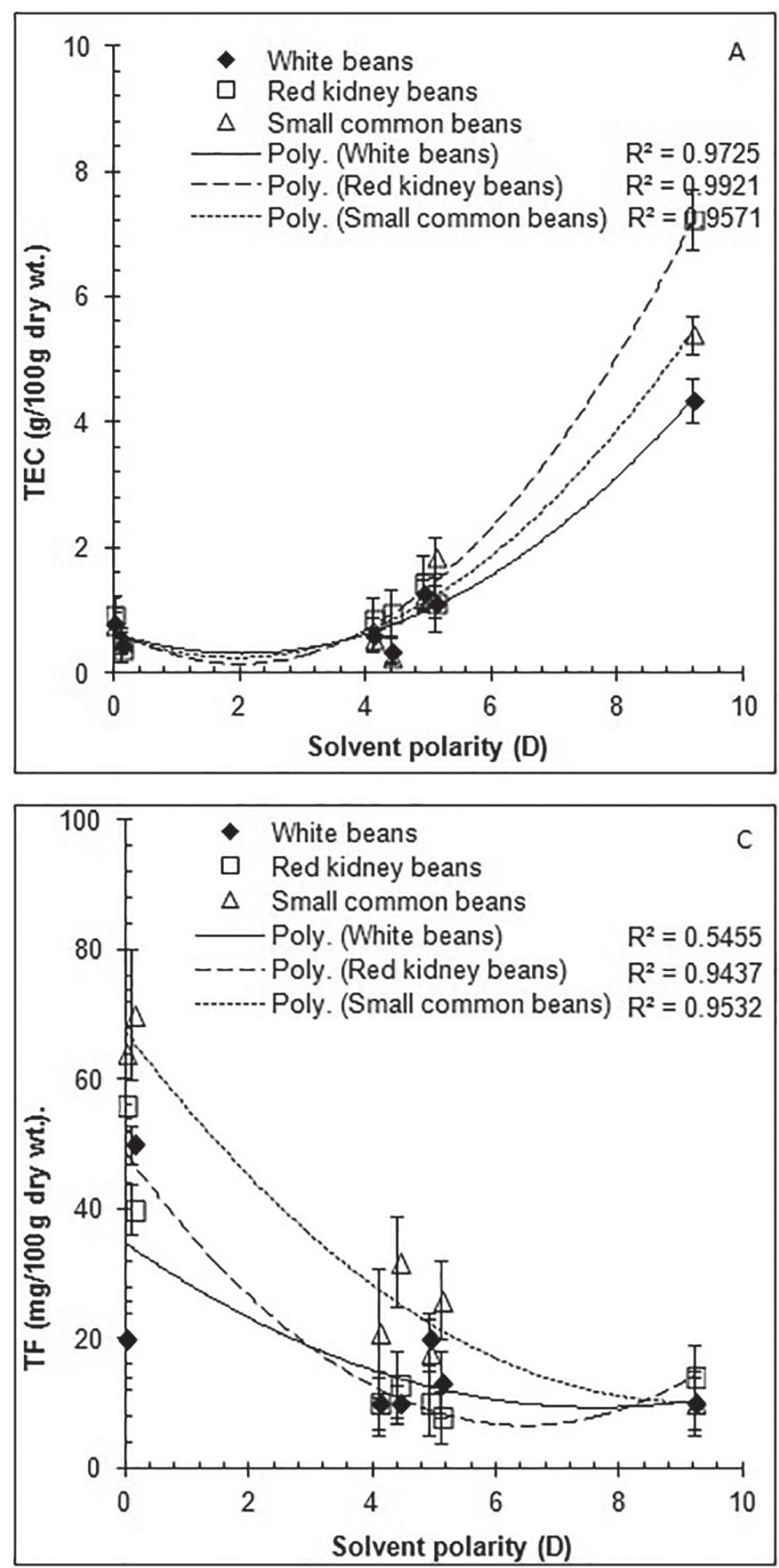

0.9283 and TF: 0.9437-0.9532) except for TFC in white bean (Figure 2B, C). However, the extracts in nonpolar solvents including hexane and petroleum ether were found to be comparatively high in TPC and TFC of each variety. This indicates a negative correlation between TEC and TPC and TFC of extracts suggesting that phenolic acids are extracted more in nonpolar solvents.

TAOA, IRC and LARC of each variety was found to be increased in polynomial fashion in response to an
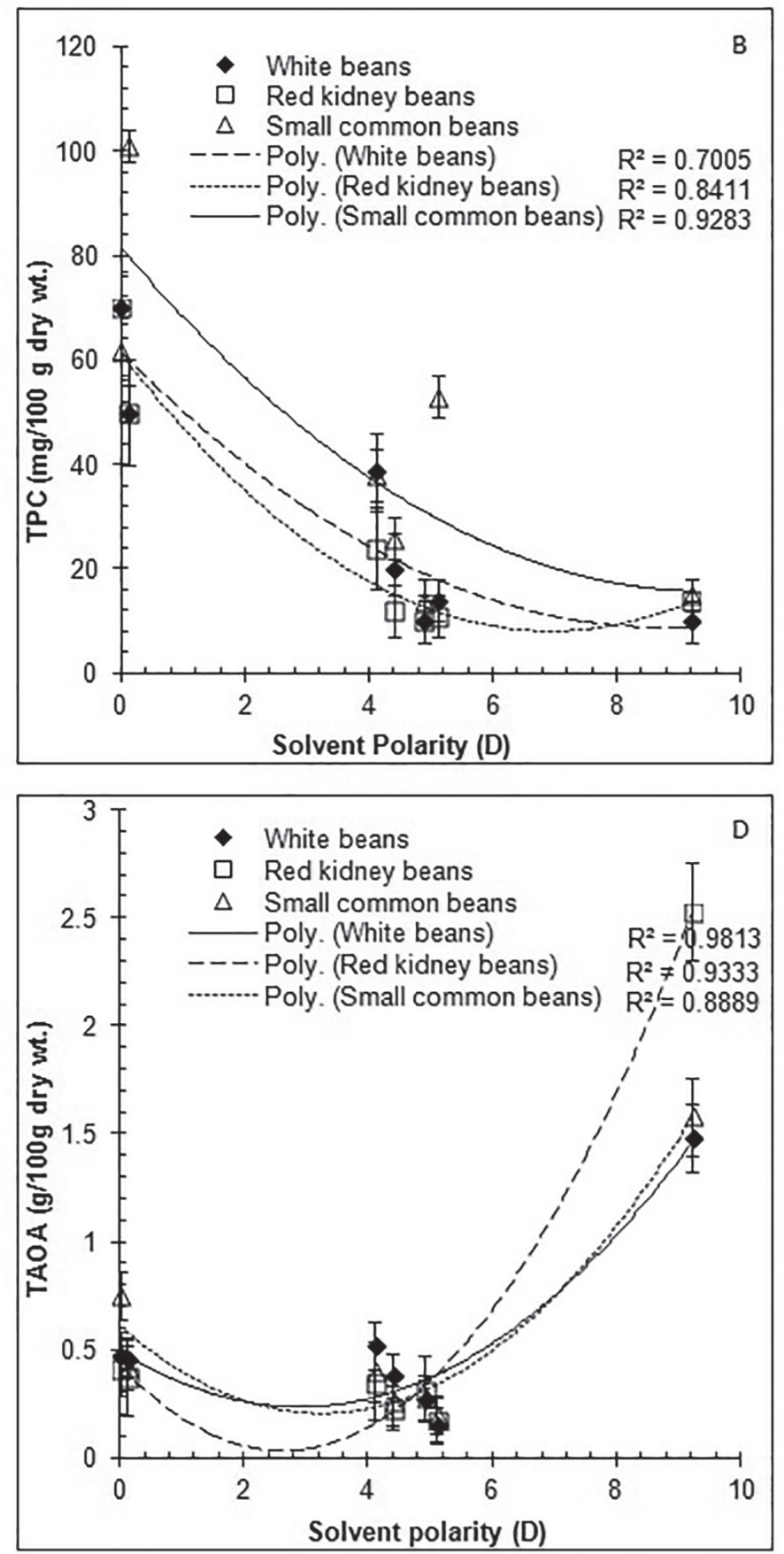

FIGURE 2 - The solvent polarity dependent response of A: total extractable components (TEC), B: total phenolic content (TPC), C: total flavonoid content (TFC) and D: Total antioxidant activity (TAOA) of three varieties of bean seeds. 

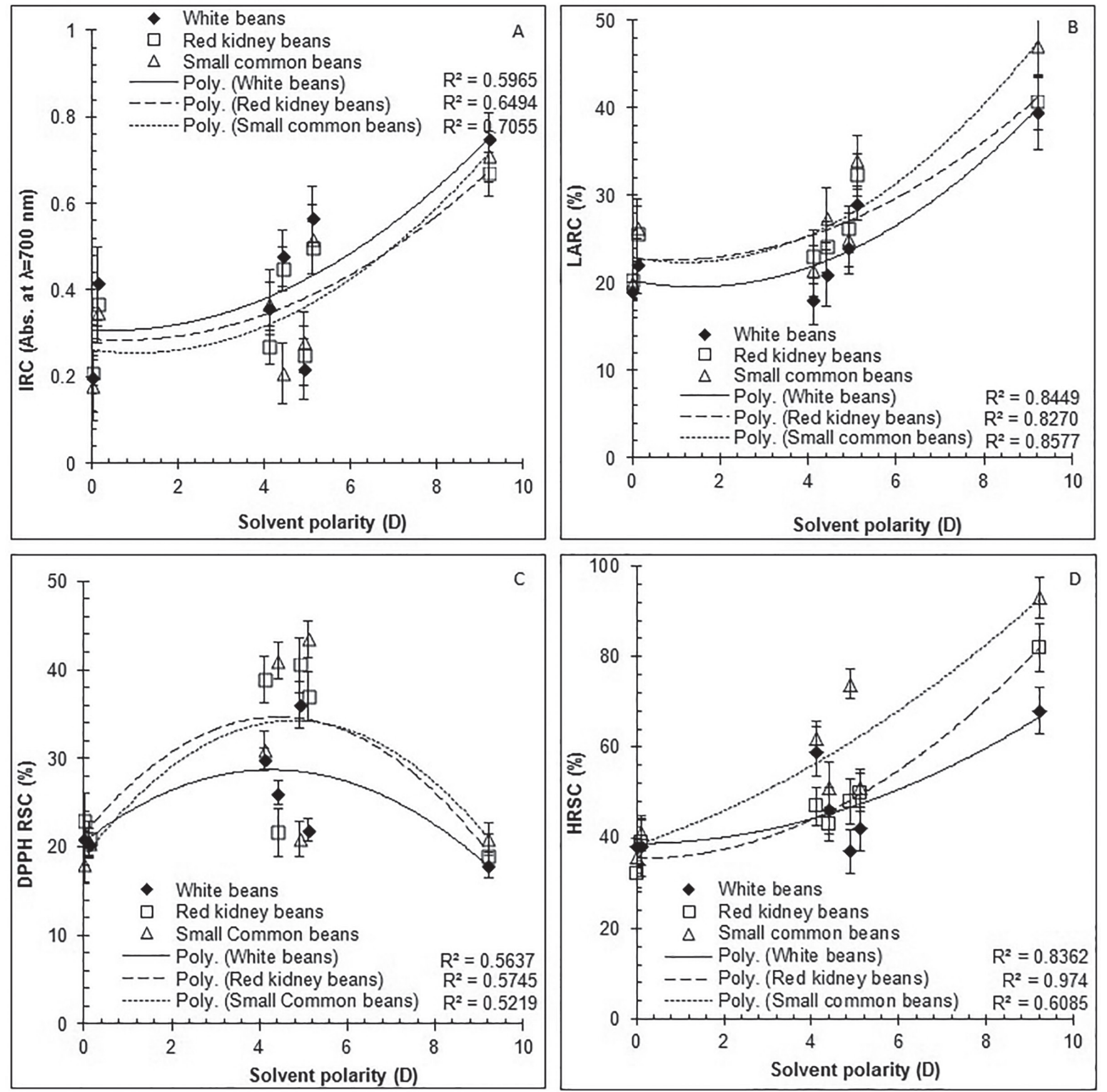

FIGURE 3 - Reducing capacity and free radical scavenging capacity of three varieties of bean seeds at various levels of solvent polarity. A: Iron reducing capacity (IRC), B: Linoleic acid reduction capacity (LARC), C: Hydroxyl radical scavenging capacity (HRSC), D: DPPH radical scavenging capacity (DPPH RSC).

increase in solvent polarity $\left(\mathrm{R}^{2}=0.8889-0.9813,0.5965\right.$ 0.7055 and 0.827-0.8577 respectively; Figure 2D, 3A, B). The identical regression curves of TEC and TAOA, IRC and LARC indicate the extraction of more polar components in polar solvents which possess good antioxidant and reducing capacities. Although being rich in phenolic acids and flavonoids, the extracts in nonpolar solvents were found to be poor in antioxidant and reducing properties.
Solvent polarity was also found to exert a polynomial increase in HRSC $\left(\mathrm{R}^{2}=0.6085-0.974\right)$ and decrease in DPPH RSC of each variety with relatively low values of $\mathrm{R}^{2}$ (0.5219-0.5745). Water extract showed a comparatively higher capacity to scavenge hydroxyl radical. However, higher scavenging ability against DPPH radical was shown by bean extracts in solvents of intermediate polarity as compared to polar and nonpolar ones. 

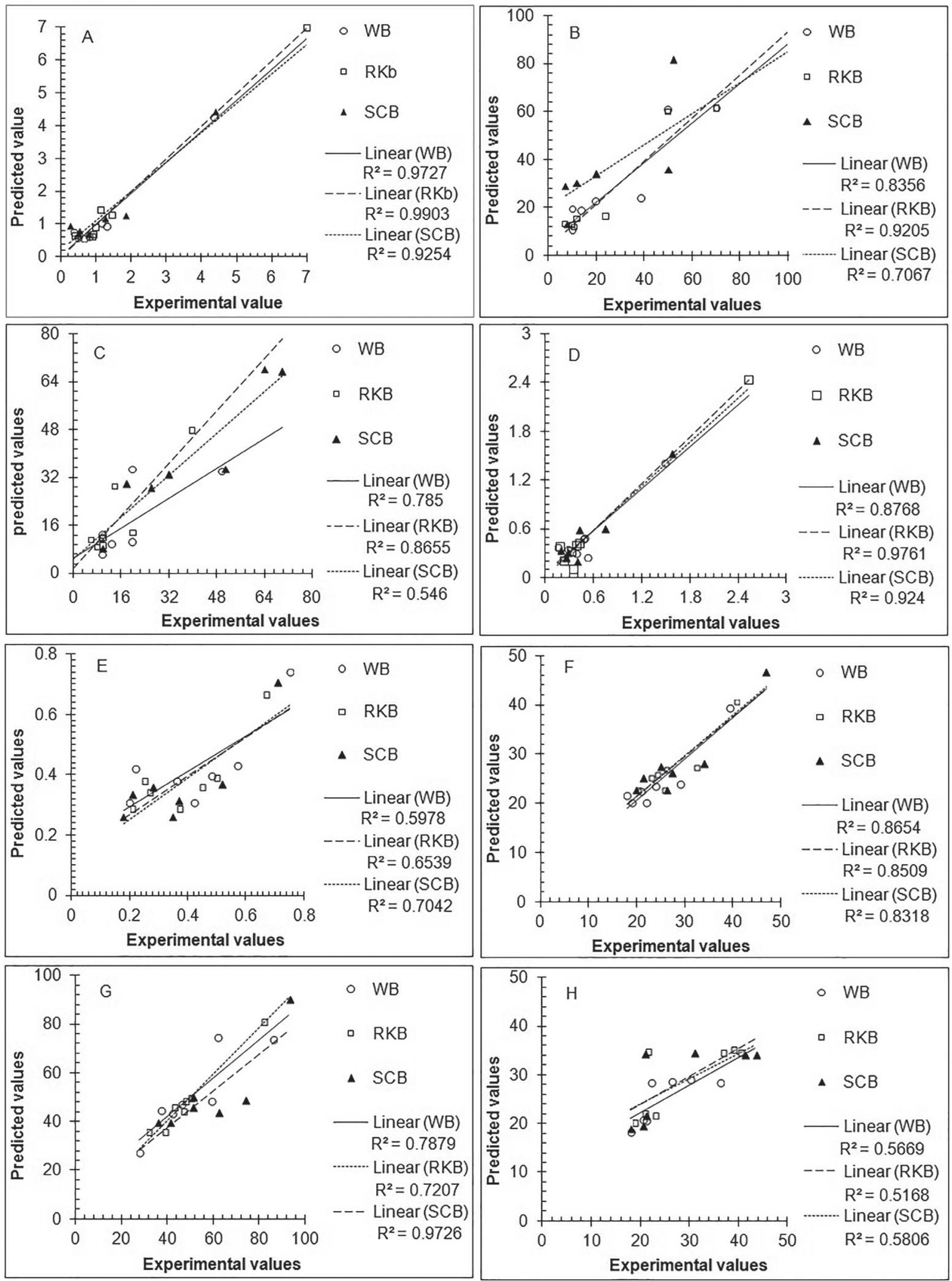

FIGURE 4 - Correlation between experimental and predicted values of phytochemical and antioxidant parameters of Bean seed extracts. A: total extractable components (TEC), B: total phenolic content (TPC), C: total flavonoid content (TFC) and D: Total antioxidant activity (TAOA), E: A: Iron reducing capacity (IRC), F: Linoleic acid reduction capacity (LARC), G: Hydroxyl radical scavenging capacity (HRSC), H: DPPH radical scavenging capacity (DPPH RSC), WB: white beans, RKB, red kidney beans, SCB: small common beans. 
The predicted values of response were calculated by putting the values of model terms in the generalized polynomial regression equations and plotted against the experimental values to check the validity of suggested regression model (Figure 4A-H). A good agreement between the experimental and predicted values of TEC, TPC, TF, TAOA, LARC and HRSC was observed indicating the suitability and applicability of the suggested regression model to study the effect of solvent polarity on the extraction of phytochemical and antioxidant properties of bean seeds.

\section{CONCLUSIONS}

The polarity-dependent increase in extraction yield, antioxidant activity, reducing properties and free radical scavenging activity of bean varieties may be attributed to the high affinity of antioxidant compounds in bean seeds towards more polar solvents as compared to nonpolar ones. However, high values of TPC and TFC in non-polar solvents indicate that most of the phenolic compounds present in bean seeds are non-polar in nature. The results suggest the suitability of polar solvents for the extraction of antioxidant compounds from plant materials particularly bean seeds. The study also suggests that phytochemical compounds extracted in polar solvents are pharmaceutically more important due to comparatively higher values of antioxidant activity, reducing properties and free radical scavenging activity.

\section{CONFLICT OF INTEREST STATEMENT}

There is no conflict of interest regarding the submitted research article.

\section{REFERENCES}

Abdel-Aal EI, Haroon AM, Mofeed J. Successive solvent extraction and GC-MS analysis for the evaluation of the phytochemical constituents of the filamentous green alga Spirogyra longata. Egypt J Aquat Res. 2015;41(3):233-246.

Atchibri AL, Brou KD, Kouakou TH, Kouadio YJ, Gnakri D, others. Screening for antidiabetic activity and phytochemical constituents of common bean (Phaseolus vulgaris L.) seeds. J Med Plants Res. 2010;4(17):1757-1761.

Barchan A, Bakkali M, Arakrak A, Pagán R, Laglaoui A. The effects of solvents polaritiy on the phenolic contents and antioxidant activity of three Mentha species extracts. Int J Curr Microbiol App Sci. 2014;3(11):399-412.
Bimakr M, Rahman RA, Taip FS, Ganjloo A, Salleh LM, Selamat J, et al. Comparison of different extraction methods for the extraction of major bioactive flavonoid compounds from spearmint (Mentha spicata L.) leaves. Food Bioprod Process. 2011;89(1):67-72.

Brewer MS. Natural Antioxidants: sources, compounds, mechanisms of action, and potential applications. Compr Rev Food Sci Food Saf. 2011;10(4):221-47.

Coles L. Functional foods: the connection between nutrition, health, and food science. New Jersey: CRC Press; 2013.

Das K, Tiwari RKS, Shrivastava DK. Techniques for evaluation of medicinal plant products as antimicrobial agent: Current methods and future trends. J Med Plants Res. 2010;4(2):104-111.

Ghasemzadeh A, Jaafar HZ, Juraimi AS, Tayebi-Meigooni A. Comparative Evaluation of Different Extraction Techniques and Solvents for the Assay of Phytochemicals and Antioxidant Activity of Hashemi Rice Bran. Molecules. 2015;20(6):1082210838.

Ghasemzadeh A, Jaafar HZ, Rahmat A. Effects of solvent type on phenolics and flavonoids content and antioxidant activities in two varieties of young ginger (Zingiber officinale Roscoe) extracts. J Med Plants Res. 2011;5(7):1147-1154.

Guajardo-Flores D, Serna-Saldívar SO, Gutiérrez-Uribe JA. Evaluation of the antioxidant and antiproliferative activities of extracted saponins and flavonols from germinated black beans (Phaseolus vulgaris L.). Food Chem. 2013;141(2):1497-503.

Guevara-González RG, editor. Advances in agricultural and food biotechnology. Trivandrum, Kerala: Research Signpost; 2006.

Harborne JB. Phytochemical methods a guide to modern techniques of plant analysis. [Internet]. New Delhi: Springer Science \& Business Media; 1998 [cited 2015 Dec 9]. Available from: https://books.google.com/books?hl=en\&lr=\&id=2yvqeR tE8CwC\&oi $=$ fnd\&pg $=$ PR7\&dq $=$ Phytochemical + methods\&ots $=$ xyeoW5TkV6\&sig=4MdjQ9VJtERrbvMTBOv6hdVwOL8.

Iloki-Assanga SB, Lewis-Luján LM, Lara-Espinoza CL, GilSalido AA, Fernandez-Angulo D, Rubio-Pino JL, et al. Solvent effects on phytochemical constituent profiles and antioxidant activities, using four different extraction formulations for analysis of Bucida buceras L. and Phoradendron californicum. BMC Res Notes. 2015;8(1):396. 
Lapornik B, Prošek M, Wondra AG. Comparison of extracts prepared from plant by-products using different solvents and extraction time. J Food Eng. 2005;71(2):214-222.

Masella R, Di Benedetto R, Varì R, Filesi C, Giovannini C. Novel mechanisms of natural antioxidant compounds in biological systems: involvement of glutathione and glutathionerelated enzymes. J Nutr Biochem. 2005;16(10):577-586.

Ortega T de JA, Aceves GEB, Sotelo MGR, Fernández JY. Methanolic extracts antioxidant and antimicrobial activities from five varieties of common beans (Phaseolus vulgaris L.). In: International Journal of Engineering Research and Technology [Internet]. ESRSA Publications; 2013 [cited 2016 Apr 4]. Available from: http://www.ijert.org/view-pdf/6610/ methanolic-extracts-antioxidant-and-antimicrobial-activitiesfrom-five-varieties-of-common-beans-phaseolus-vulgaris-1.

Osawa T, Namiki M. A novel type of antioxidant isolated from leaf wax of Eucalyptus leaves. Agric Biol Chem. 1981;45(3):735-739.

Oyaizu M. Studies on products of browning reactionantioxidative activities of products of browning reaction prepared from glucosamine. Eiyogaku Zasshi Jpn J Nutr [Internet]. 1986 [cited 2015 Dec 21]; Available from: http://agris. fao.org/agris-search/search.do?recordID=US201302009163

Pradeepkumar M, Joshi S, Kulkarni V, Savant C. Phytochemical screening and evaluation of analgesic and antiinflammatory activities of Phaseolus vulgaris linn., seeds in rodents. J Appl Pharm Sci. 2015;5(6):66-9.

Prieto P, Pineda M, Aguilar M. Spectrophotometric quantitation of antioxidant capacity through the formation of a phosphomolybdenum complex: specific application to the determination of vitamin E. Anal Biochem. 1999;269(2):337341 .
Sánchez-Moreno C, Larrauri JA, Saura-Calixto F. A procedure to measure the antiradical efficiency of polyphenols. J Sci Food Agric. 1998;76(2):270-276.

Shad MA, Pervez H, Zafar ZI, Nawaz H, Khan H. Physicochemical properties, fatty acid profile and antioxidant activity of peanut oil. Pak J Bot. 2012;44(1):435-440.

Smirnoff N, Cumbes QJ. Hydroxyl radical scavenging activity of compatible solutes. Phytochemistry. 1989;28(4):1057-1060.

Soares LAL, Bassani VL, Ortega GG, Petrovick PR. Total flavonoid determination for the quality control of aqueous extractives from Phyllanthus niruri L. Acta Farm Bonaer. 2003;22(3):203-208.

Sofowora A. Medicinal plants and traditional medicine in Africa. [Internet]. John Wiley and Sons; 1982 [cited 2015 Dec 9]. Available from: http://www.cabdirect.org/ abstracts/19842012621.html.

Trease GE, Evans WC. Introduction and general methods in pharmacognosy, 13th Eds. UK: Cambridge University Press; 1989.

Zhu Z, Jiang W, Thompson HJ. Edible dry bean consumption (Phaseolus vulgaris L.) modulates cardiovascular risk factors and diet-induced obesity in rats and mice. Br J Nutr. 2012;108(S1):S66-S73.

Zou YP, Chang SKC. Antioxidant and antiproliferative properties of extract and fractions from small red bean (Phaseolus vulgaris L.). J Food Nutr. 2014;1:1-11.

Received for publication on $24^{\text {th }}$ March 2017 Accepted for publication on $02^{\text {nd }}$ February 2018 